ORIGINAL ARTICLE

\title{
Effects of montelukast on airway narrowing from eucapnic voluntary hyperventilation and cold air exercise
}

\author{
K W Rundell, B A Spiering, J M Baumann, T M Evans
}

Br J Sports Med 2005;39:232-236. doi: 10.1136/bjsm.2004.014282

See end of article for authors' affiliations

Correspondence to: Dr Rundell, Human Performance Laboratory, Marywood University, 2300 Adams Avenue, Scranton, PA 18509, USA; rundell@marywood.edu

Accepted

7 September 2004

\begin{abstract}
Background: Exercise induced bronchoconstriction (EIB) is common in elite athletes. Eucapnic voluntary hyperventilation $(\mathrm{EVH})$ is a laboratory test recommended for the identification of EIB in athletes, secondary to a field exercise challenge. Montelukast attenuates EIB, but its protective effect against airway narrowing from EVH has not been investigated.

Objective: To examine the effectiveness of montelukast after exercise and after $\mathrm{EVH}$.

Methods: A randomised, placebo controlled, double blind, crossover study was performed with 11 physically active EIB positive subjects (eight men, three women; mean (SD) age 22.8 (6.8) years). Six hours before each of the following challenges $10 \mathrm{mg}$ montelukast or placebo was ingested: (a) a six minute, cold air $\left(-3^{\circ} \mathrm{C}\right)$ maximal effort work accumulation cycle ergometer exercise; (b) $\mathrm{EVH}$, breathing $5 \% \mathrm{CO}_{2}$ compressed air at $85 \%$ maximal voluntary ventilation for six minutes. Spirometry was performed before and 5, 10, and 15 minutes after the challenge. At least 48 hours was observed between challenges.

Results: No differences in forced expiratory volume in one second $\left(\mathrm{FEV}_{1}\right)$ were found after the two challenges. Exercise and $\mathrm{EVH}$ resulted in falls in $\mathrm{FEV}_{1}$ of $22.4(18.0)$ and 25.6 (16.8) respectively. Falls in $\mathrm{FEV}_{1}$ after montelukast were less than after placebo $(10.6$ (10.6) and 14.3 (11.3) affer exercise and $\mathrm{EVH}$ respectively; $\mathrm{p}<0.05)$. Montelukast provided protection against bronchoconstriction $(59 \%$ and $53 \%$; $\mathrm{p}<0.05$ ) for eight exercising subjects and $10 \mathrm{EVH}$ subjects; no protection was afforded for three exercising and one $\mathrm{EVH}$ challenged subject.

Conclusions: Both exercise and EVH were potent stimuli of airway narrowing. A single dose of montelukast provided reasonable protection in attenuating bronchoconstriction from either exercise or EVH. The similar protection by montelukast suggests that EVH is a suitable laboratory surrogate for EIB evaluation.
\end{abstract}

$\mathrm{E}$ xercise induced bronchoconstriction (EIB) after exercise in elite athletes has received substantial attention over the last decade. EIB is common among elite athletes; about $25 \%$ of the 1998 US Winter Olympians were identified by spirometry ${ }^{1}$ or questionnaire ${ }^{2}$ as having EIB. More than $15 \%$ of the 1996 US Summer Olympians reported a diagnosis of asthma or EIB. ${ }^{3}$ Self reported symptoms are most often the primary criteria used by clinicians in diagnosing EIB, even though reports show that objective criteria from bronchial provocation tests are needed to make the correct diagnosis in elite athletes. ${ }^{45}$

The high use of $\beta 2$ agonists among Olympic athletes led the International Olympic Committee-Medical Commission (IOC-MC) to establish objective criteria for allowed use during competition. Inhaled $\beta 2$ agonists are indicated for prophylaxis of exercise induced asthma or EIB because of the effective relaxation of bronchial smooth muscle. Eucapnic voluntary hyperventilation $(\mathrm{EVH})$ is the laboratory test recommended for the identification of EIB in Olympic athletes, ${ }^{6-9}$ secondary to a field exercise challenge. ${ }^{10}$ The EVH challenge involves inhalation of dry air containing $5 \% \mathrm{CO}_{2}$ at exercising minute ventilations (VE) for six minutes. ${ }^{5-811}$ The effectiveness of this test is based on the assumption that the resultant airway narrowing from EVH is caused by osmotic events that stimulate the release of bronchoconstricting mediators, similar to the mechanism hypothesised for the response after exercise. ${ }^{12}$ The ability to standardise and control environmental conditions make this test a suitable alternative to a field based exercise test that can be performed with ease in a clinical or laboratory setting,, ${ }^{5} 8$ although a field based exercise challenge in cold dry ambient conditions has been shown to be superior to a laboratory exercise challenge at ambient conditions of $21^{\circ} \mathrm{C}$ and $50 \%$ relative humidity. ${ }^{10}$

Leukotrienes are involved in the pathogenesis of asthma and EIB by inducing airway smooth muscle contraction. ${ }^{13}{ }^{14}$ Montelukast, a long-acting cysteinyl leukotriene receptor antagonist that blocks the action of leukotrienes $\mathrm{C}_{4}$ and $\mathrm{D}_{4}{ }^{15}$ effectively protects against airway narrowing exercise. Previous reports evaluating the inhibitory effect of montelukast on EIB have identified an approximate 50\% improvement in post-exercise forced expiratory volume in one second $\left(\mathrm{FEV}_{1}\right)$ after treatment. ${ }^{16-20}$

The aim of this study was to compare airway responses by airway hyper-responsive (AHR) positive subjects to EVH in the laboratory to an exercise challenge in cold/dry air after ingesting either placebo or montelukast. Using montelukast treatment to indirectly evaluate leukotriene involvement in EVH and exercise is important to the elite athlete as (a) EVH has been designated as the preferred challenge by the IOCMC for obtaining objective evidence for permission of $\beta 2$ agonist use in Olympic competition and $(b)$ a single dose of montelukast may prove to be an effective treatment modality for EIB.

\section{METHODS}

This study was conducted in the spring of 2003. Each subject performed two room temperature EVH challenges and two

Abbreviations: AHR, airway hyper-responsive; EIB, exercise induced bronchoconstriction; EVH, eucapnic voluntary hyperventilation; EX, cold air exercise; $\mathrm{FEF}_{25-75}$, forced expiratory flow through the mid portion of the vital capacity; FEV 1 , forced expiratory volume in one second; FVC, forced vital capacity 
high intensity six minute cycle ergometer challenges in cold temperature conditions (EX) in the Marywood University Human Performance Laboratory climate control chamber. Subjects ingested a single dose of either $10 \mathrm{mg}$ montelukast or placebo six to eight hours before each trial. The order was randomised and double blinded, and the trials were separated by $48-72$ hours. We have previously shown that 48 hours between challenges was sufficient to negate an order effect. ${ }^{8}$ Spirometry was performed before and after the challenge.

\section{Subjects}

After receiving a written and verbal study description, 11 EIB positive (defined by $\mathrm{a} \geqslant 10 \%$ fall in $\mathrm{FEV}_{1}$ ) recreational and college athlete subjects (three women, eight men; mean (SD) age, weight, and height 22.8 (6.8) years, 80.5 (15.7) kg, and $173.9(6.3) \mathrm{cm}$ respectively) volunteered to undergo EVH and EX. The inclusion criteria of $\mathrm{a} \geqslant 10 \%$ fall in $\mathrm{FEV}_{1}$ is consistent with the IOC-MC recommended cut-off point and was designed to include those with mild to moderate EIB, as this represents the elite athlete population. Four subjects had a previous diagnosis of mild asthma, and were prescribed a short acting $\beta 2$-agonist, but reported non-compliant use. This study was approved by the Marywood University institutional review board, and all subjects gave written informed consent.

\section{Test conditions}

Ambient test conditions for EVH were $21{ }^{\circ} \mathrm{C}$ and $40 \%$ relative humidity. EVH gas was compressed, dry air $\left(21 \% \mathrm{O}_{2}, 5 \% \mathrm{CO}_{2}\right.$, balance $\mathrm{N}_{2}$ ). Environmental conditions for EX in the climate control room were set at $-3^{\circ} \mathrm{C}$ and $50 \%$ relative humidity (VWR digital hygrometer/thermometer, VWR International Inc, West Chester, PA, USA). The water content of the inspired air in both challenges made conditions suitable for AHR provocation. ${ }^{12}$

\section{Pulmonary function tests}

Pulmonary function was measured by spirometry using a calibrated computerised pneumotachograph spirometer (Jaeger Masterscope PC, Hoechberg, Germany). Forced vital capacity $(\mathrm{FVC}), \mathrm{FEV}_{1}, \mathrm{FEV}_{1} / \mathrm{FVC}$ ratio, and forced expiratory flow through the mid portion of the vital capacity $\left(\mathrm{FEF}_{25-75}\right)$ were determined before and after the challenge. The procedure for all pulmonary function tests was $(a)$ three normal tidal volume breaths, $(b)$ maximal inhalation, (c) forced maximal exhalation, and (d) maximal inhalation. Resting baseline pulmonary function was established before

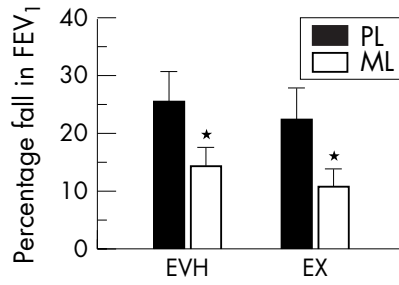

Figure 1 Peak percentage fall in forced expiratory volume in one second $\left(\mathrm{FEV}_{1}\right)$ from baseline during 15 minutes after eucapnic voluntary hyperventilation (EVH) or high intensity six minute cycle ergometer challenge in cold temperature conditions (EX) after ingestion of placebo (PL) or montelukast (ML). *Significantly different from placebo $(p<0.05)$.

each challenge by selecting the best of three resting pulmonary function tests based on the highest sum of FVC and $\mathrm{FEV}_{1}$. Pulmonary function after each challenge was measured 5, 10, and 15 minutes after the completion of EVH and EX. If any measurement was technically unacceptable, the pulmonary function test manoeuvre was repeated.

\section{Eucapnic voluntary screening challenge}

The EVH protocol required subjects to breathe the compressed EVH gas mixture at a predetermined rate of $85 \%$ maximal voluntary ventilation (estimated from $30 \times$ resting FEV $_{1}$ ) for six minutes. ${ }^{6}{ }^{8}$ Gas flowed from a cylinder through a calibrated rotameter (1110 series flowmeter; Brooks Instruments, Hatfield, Pennsylvania, USA) to a $300 \mathrm{~g}$ reservoir bag through high pressure tubing. From the reservoir bag, the gas was directed to the subject through a $35 \mathrm{~mm}$ breathing tube, two way breathing valve, and mouthpiece (Hans Rudolf, Kansas City, Missouri, USA). Expired gas passed through a flow sensor, and VE was recorded as a verification of the target VE (VmaxST Measurement Cart, SensorMedics, Yorba Linda, California, USA). Inhaled gas during EVH was at laboratory temperature but completely dry. Ambient conditions in the laboratory were $21^{\circ} \mathrm{C}$ and $40 \%$ relative humidity.

\section{Cycle ergometer exercise challenge}

The high intensity EX challenge consisted of a six minute trial using an electronically braked cycle ergometer (Lode Excalibur Sport; Lode, Groningen, the Netherlands). Subjects were instructed to exercise at the highest intensity sustainable for the duration of the test and were verbally encouraged to give a maximal effort. Subjects wore wireless heart rate monitors to verify exercise intensity (Polar Vantage XL; Polar Electro Oy, Kempele, Finland), and total work accumulated $(\mathrm{kJ})$ was recorded on completion of the six minute time trial.

\begin{tabular}{llllll} 
Table 1 & Baseline lung functions & & & \\
\hline & FVC & FEV $_{1}$ & FEV $_{1} /$ FVC & FEF $_{25-75}$ & PEF \\
\hline EVH placebo & $5.0(0.81)$ & $4.1(0.76)$ & $81.3(8.58)$ & $3.9(1.29)$ & $8.8(1.33)$ \\
& $106(14.9)$ & $102(14.5)$ & & $84.2(27.6)$ & $100(16.4)$ \\
EVH montelukast & $4.8(0.76)$ & $3.8(0.67)$ & $79.4(7.46)$ & $3.4(1.08)$ & $8.5(1.30)$ \\
& $103(15.8)$ & $95.5(15.6)$ & & $72.9(24.7)$ & $96.4(15.1)$ \\
EX placebo & $4.9(0.84)$ & $4.0(0.83)$ & $80.4(6.42)$ & $3.7(1.45)$ & $8.8(1.17)$ \\
& $105(16.0)$ & $99.4(15.4)$ & & $78.8(26.8)$ & $99.2(9.4)$ \\
EX montelukast & $4.8(0.84)^{*}$ & $3.9(0.69)$ & $80.9(6.48)$ & $3.5(0.99)$ & $8.7(1.03)$ \\
& $103(14.4)$ & $97.3(13.6)$ & & $76.0(20.6)$ & $98.7(11.7)$ \\
Grand mean & & & & & \\
Placebo & $5.0(0.81)$ & $4.0(0.78)$ & $80.9(7.41)$ & $3.8(1.34)$ & $8.8(1.22)$ \\
& $106(15.0)$ & $101(14.6)$ & & $81.5(26.7)$ & $99.6(13.1)$ \\
Montelukast & $4.8(0.78)^{*}$ & $3.8(0.67)^{*}$ & $80.1(6.86)$ & $3.4(1.02)$ & $8.6(1.15)$ \\
& $103(14.8)$ & $96.4(14.3)$ & & $74.5(22.3)$ & $97.6(13.3)$ \\
\hline
\end{tabular}

*Significantly different from corresponding placebo treatment $(p<0.05)$.

EVH, Eucapnic voluntary hyperventilation; EX, high intensity six minute cycle ergometer challenge in cold

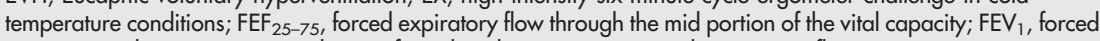
expiratory volume in one second; FVC, forced vital capacity; PEF, peak expiratory flow. 


\section{Statistical methods}

Descriptive statistics for resting lung function were calculated for each trial (placebo and montelukast) for challenge conditions. Repeated measures analysis of variance was used to analyse differences between trials and groups. An $\alpha$ of $p \leqslant$ 0.05 was considered significant.

\section{RESULTS}

Table 1 gives resting baseline lung function values. Mean values for $\mathrm{FVC}, \mathrm{FEV}_{1}, \mathrm{FEV}_{1} / \mathrm{FVC}, \mathrm{FEF}_{25-75}$, and peak expiratory flow were within the normative predicted values for age, height, and sex. However, one subject showed $<80 \%$ predicted FVC, four subjects had $<80 \%$ predicted $\mathrm{FEV}_{1}$, two subjects had $<70 \% \mathrm{FEV}_{\mathrm{l}} / \mathrm{FVC}$, and six subjects had $<67 \%$ predicted $\mathrm{FEF}_{25-75}$ (of these six, three had $\mathrm{FEF}_{25-75}$ values below $50 \%$ predicted). Resting FVC and $\mathrm{FEV}_{1}$ were significantly lower for montelukast than for placebo when values from all four trials were pooled $(\mathrm{p}<0.05)$. Within trial modalities (EVH and EX), resting FVC before EX was significantly lower for montelukast than for placebo $(p<0.05)$. No significant correlations were identified between resting lung functions and falls in $\mathrm{FEV}_{1}$ after the challenge for any trial.

Eleven subjects performed two trials of both EVH and EX for six minutes six to eight hours after ingesting either placebo or montelukast. Percentage peak fall in $\mathrm{FEV}_{1}$ from resting $\mathrm{FEV}_{1}$ between $\mathrm{EVH}$ and EX was not different for placebo or for montelukast (25.6 (16.75)\% v 22.4 (18.03)\% for EVH placebo and EX placebo; 14.3 (11.28)\% v 10.6 (10.6)\% for EVH montelukast and EX montelukast respectively). Montelukast provided about $44 \%$ protection from AHR for EVH and about 53\% protection from AHR for EX, expressed as the difference in percentage fall in $\mathrm{FEV}_{1}$ between placebo and montelukast (range $0-100 \%$ for $\mathrm{EVH}$ and $\mathrm{EX}, \mathrm{p}<0.05$; fig 1).

Figure 2 shows change in $\mathrm{FEV}_{1}$ after EVH and EX for placebo and montelukast trials. For EVH, $\mathrm{FEV}_{1}$ at 5, 10, and 15 minutes after the challenge was significantly different between placebo and montelukast $(\mathrm{p}<0.05)$; for $\mathrm{EX}, \mathrm{FEV}_{1}$ at 10 and 15 minutes was significantly different between placebo and montelukast $(\mathrm{p}<0.05)$. No difference was noted for any time point between EVH placebo and EX placebo, or between EVH montelukast and EX montelukast. Likewise, no difference in percentage fall in $\mathrm{FEV}_{1}$ between the 5, 10, and 15 minute time points was identified for any trial. The mean areas above the curves were 267 (195), 137 (118), 212 (196), and 107 (115) for EVH placebo, EVH montelukast, EX

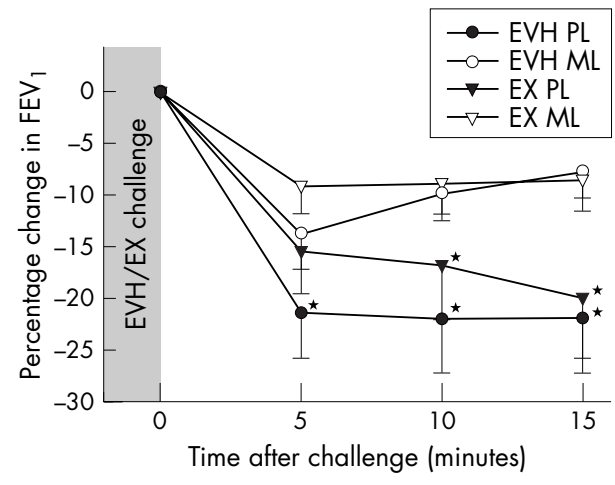

Figure 2 Percentage change from baseline in forced expiratory volume in one second $\left(\mathrm{FEV}_{1}\right) 5,10$, and 15 minutes after the completion of eucapnic voluntary hyperventilation (EVH) and high intensity six minute cycle ergometer challenge in cold temperature conditions (EX) trials on placebo (PL) and montelukast (ML) treatments. *Significant differences between placebo and montelukast for respective challenges at each time point.

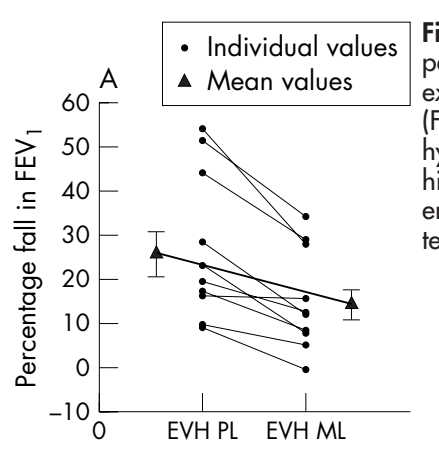

Figure 3 Individual peak percentage falls in forced expiratory volume in one second $\left(\mathrm{FEV}_{1}\right)$ for eucapnic voluntary hyperventilation (EVH) (A) and high intensity six minute cycle ergometer challenge in cold temperature conditions (EX) (B).

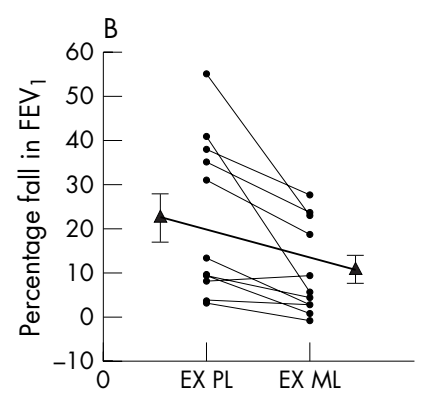

placebo, and EX montelukast respectively. Significant differences were noted between placebo and montelukast for both EVH and EX $(p<0.05)$, but not between EVH and EX for the respective placebo and montelukast treatments.

Figure 3 presents individual plots for EVH and EX after ingestion of placebo or montelukast. After placebo treatment, 10 subjects were positive to EVH $(\mathrm{EVH}+)$, eight were positive to EX $(\mathrm{EX}+)$, and seven had concordant findings and were positive to both EVH and EX. Seven subjects showed greater falls in $\mathrm{FEV}_{1}$ from EVH, two showed greater falls from EX, and two had similar falls for EVH and EX. For EVH, all but one subject showed some degree of protection from the single $10 \mathrm{mg}$ dose of montelukast ingested six to eight hours before the challenge. That subject showed $16 \%$ and $15.6 \%$ falls in $\mathrm{FEV}_{1}$ from EVH for placebo and montelukast respectively, but showed no clinically relevant falls in $\mathrm{FEV}_{1}$ from EX. Three other subjects who tested positive by EVH on placebo and negative by EX on placebo showed no effect from montelukast treatment during EX.

Figure 4 plots the difference between falls in $\mathrm{FEV}_{1}$ after EVH and EX against an estimate of the true value determined as the mean of the two challenges for placebo and montelukast $(3.21 \quad(14.51) \%$ and 3.65 (8.84)\% for placebo and montelukast respectively); no significant difference was identified between the mean of the differences between the two values. The difference between challenges was normally distributed around the mean of EVH and EX challenges. For placebo, all differences between challenges fell within 2 SD of the mean difference; for montelukast, only one value exceeded 2 SD of the mean, showing reasonable agreement between the hyper-responsiveness to EVH and EX and between the effects of montelukast on the response to both challenges.

\section{DISCUSSION}

Airway narrowing in EIB+ subjects after EVH is similar to the transient airway obstruction after exercise in cold/dry air; the small differences between peak fall in $\mathrm{FEV}_{1}$ between EVH and EX for placebo and after a single dose ingestion of montelukast were not significant. EVH identified seven of eight subjects with EIB after EX, with an additional three subjects AHR+ by EVH and AHR- by EX, showing that EVH 


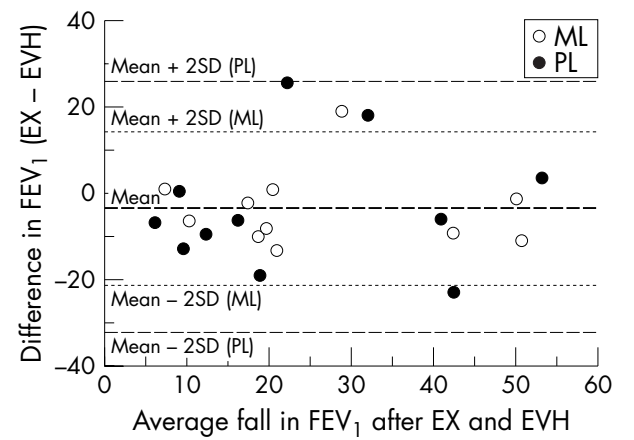

Figure 4 Difference in percentage fall in forced expiratory volume in one second $\left(\mathrm{FEV}_{1}\right)$ between high intensity six minute cycle ergometer challenge in cold temperature conditions (EX) and eucapnic voluntary hyperventilation $(\mathrm{EVH})$ plotted against the mean value for the EX and $\mathrm{EVH}$ percentage fall in $\mathrm{FEV}_{1}$ for each subject. All values for placebo fell within 2 SD of the mean and all but one value for montelukast fell within $2 \mathrm{SD}$ of the mean, indicating reasonable agreement between challenges.

is a potent stimulus for EIB in people who are hyper-reactive to exercise. These results are similar to our earlier study comparing EVH with a field based exercise challenge where we identified 17 of 19 EIB+ subjects by EVH and only 11 subjects by exercise. ${ }^{8}$ The similar levels of inhibition of $\mathrm{FEV}_{1}$ from montelukast for EVH and EX suggests that the extent of leukotriene involvement is probably similar in the two challenges. A single $10 \mathrm{mg}$ dose of montelukast provided protection from EIB in ten of 11 subjects after EVH and seven of eight subjects after EX. The $\sim 50 \%$ protection from bronchoconstriction by montelukast for both challenges is in agreement with the degree of protection reported by others for exercise. ${ }^{16-20}$ This study is the first to compare the effects of montelukast on EIB caused by EVH and exercise. Our findings provide evidence that the modular role of leukotrienes in the bronchoconstrictive response to $\mathrm{EVH}$ is probably similar to that observed in response to exercise. Moreover, inhalation of dry air is paramount to the EIB response in most cases.

In this study, a $10 \mathrm{mg}$ dose was taken orally six to eight hours before EVH or EX. As bronchodilation occurs within four hours of montelukast administration ${ }^{14}$ and peak serum concentration of montelukast has been found to occur four hours after administration, ${ }^{21}$ we feel that ingestion of montelukast six to eight hours before the challenges in this study was sufficient to be maximally effective.

The post-challenge change in $\mathrm{FEV}_{1}$ was used as a measure of abnormal lung function response and is the most widely accepted index used to define EIB. ${ }^{22}{ }^{23} \mathrm{FEV}_{1}$ is the lung function variable accepted by the IOC-MC to identify EIB. ${ }^{9}$ The $10 \%$ fall in $\mathrm{FEV}_{1}$ from the resting value after EVH or EX used to define EIB is consistent with the recommendations of others, ${ }^{822-25}$ and is the cut-off point used to define EIB in athletes requesting approval for $\beta 2$ agonist use during international competition. ${ }^{679}$ The cut-off point is based on the mean value of $\mathrm{FEV}_{1}$ plus $2 \mathrm{SD}$ from the response to an exercise challenge from non-hyper-responsive subjects. Others have statistically justified a more liberal cut-off value for the fall in $\mathrm{FEV}_{1}$ of about $7 \%$ in elite athletes. ${ }^{46}$ Although strong correlations have been identified between mid expiratory flow rates $\left(\mathrm{FEF}_{25-75}\right.$ and $\left.\mathrm{FEF}_{50}\right)$, these values are dependent on vital capacity and need to be interpreted with caution, ${ }^{27}$ thus we did not report mid expiratory flow rate values. Likewise, we chose not to report peak expiratory flow, as it is highly effort dependent and highly variable. ${ }^{4}$

Baseline lung function in asthmatics is often associated with hyper-reactive airways. Similar to previous studies using
What is already known on this topic

It is known that EVH is a potent surrogate challenge for identification of EIB and that inspired dry air is critical to an EIB provoking challenge. It is also known that, overall, montelukast provides about $50 \%$ protection against EIB.

\section{What this study adds}

This study shows that the contribution of leukotrienes to the post-challenge response to $\mathrm{EVH}$ and cold/dry air exercise is equal, suggesting similar mechanisms and supporting EVH as a challenge for EIB. Importantly, this study confirms that a single $10 \mathrm{mg}$ dose of montelukast is effective prophylaxis for EIB.

elite athletes, ${ }^{4}{ }^{8}$ we did not find a relation between baseline lung function variables and post-challenge falls in $\mathrm{FEV}_{1}$. The mean resting lung function values were considered normal (table 1); however, six subjects showed abnormally low values. Unlike previous findings ${ }^{28}$ where no change in resting lung function was noted after treatment with montelukast, we found small, but significant decreases in resting FVC and $\mathrm{FEV}_{1}$ when trials for EVH and EX were pooled for placebo and montelukast. As these changes were not significant when EVH and EX baseline functions were analysed separately, clinical relevance is unlikely and they could be due to the small sample size of this study.

The precise mediators of EIB depend on the stimulus. ${ }^{29}$ Not all subjects in this study responded equally to EVH and EX or the montelukast; this is expected in a heterogeneous group. However, analysis of the mean response for EVH and EX and individual differences between the two challenges for both placebo and montelukast indicate normal distribution within 2 SD of the mean. Cold air exercise has been shown to be only partially leukotriene mediated, ${ }^{30-32}$ the antigen response is highly leukotriene mediated, ${ }^{33}$ and aspirin induced bronchoconstriction is entirely leukotriene mediated..$^{29}{ }^{34}$ Leukotrienes and prostaglandins are generally seen as primary mediators in bronchoconstriction. However, several other mediators may directly or indirectly contribute to the EIB response. ${ }^{12}$

The partial and equal protection achieved by montelukast for EVH and EX in this study infers that other mediators in addition to leukotrienes are involved in the bronchoconstrictive response from these challenges and that the challenges are similarly mediated. The water content of the EVH air was minimal, as compressed air from a tank contains little water. Our measurement of relative humidity at the inspiratory port during EVH was about $12 \%$ at $21{ }^{\circ} \mathrm{C}$, and the water content during EX was less than $5 \mathrm{mg}$ per litre of air $\left(-2.66(0.22){ }^{\circ} \mathrm{C}\right.$ and $50 \%$ relative humidity). Recommendations of less than $10 \mathrm{mg}$ water per litre of air for an exercise provocation test have been made. ${ }^{6812}$ Although VE was not measured during $\mathrm{EX}$, it is likely that it was equal to or greater than the VE experienced during EVH, as EX was performed as a maximal effort cycle ergometer ride for six minutes.

In summary, EVH appears to be a reliable laboratory surrogate challenge for cold/dry air exercise as a provocation test for EIB. Although the potency of EVH in identifying airway narrowing is established, this is the first study to directly or indirectly evaluate the role of leukotrienes in both EVH and exercise challenges. Our results indicate that falls in $\mathrm{FEV}_{1}$ are not different between the two challenge modes. The protection afforded by montelukast was similar for EVH and 
EX, implying that leukotriene mediation of bronchoconstriction after EVH and EX is equal and probably involved in sustaining the airway narrowing rather than initiating it. Given that the preferred challenge for diagnosing EIB for allowed use of $\beta 2$ agonists during Olympic competition is $\mathrm{EVH}$, this information is important. Equally important is the confirmation that a single $10 \mathrm{mg}$ dose of montelukast can be used as prophylaxis for EIB.

\section{ACKNOWLEDGEMENTS}

We thank the subjects who volunteered for this study. The work was supported by Merck and Co, Inc grant No SING-US-63-01. Montelukast and placebo were a gift from Merck and Co.

\section{Authors' affiliations}

K W Rundell, J M Baumann, T M Evans, Human Performance Laboratory, Marywood University, Scranton, PA, USA

B A Spiering, University of Connecticut, Farmington, CT, USA

Competing interests: none declared

\section{REFERENCES}

1 Wilber RL, Rundell L, Szmedra L, et al. Incidence of exercise-induced bronchospasm in Olympic Winter Sport athletes. Med Sci Sports Exerc 2000;32:732-7

2 Weiler JM, Ryan EJ 3rd. sthma in United States olympic athletes who participated in the 1998 olympic winter games. J Allergy Clin Immunol 2000;106:267-71.

3 Weiler J, Layton T, Hunt M. Asthma in United States Olympic athletes who participated in the 1996 Summer Games. J Allergy Clin Immunol 1998; 102:722-6.

4 Rundell KW, Im J, Mayers LB, et al. Self-reported symptoms and exerciseinduced asthma in the elite athlete. Med Sci Sports Exerc 2001;33:208-13.

5 Holzer K, Anderson SD, Douglass J. Exercise in elite summer athletes: challenges for diagnosis. J Allergy Clin Immunol 2002;1 10:374-80.

6 Anderson SD, Argyros GJ, Magnussen H, et al. Provocation by eucapnic voluntary hyperpnoea to identify exercise-induced bronchoconstriction. Br J Sports Med $2001 ; 35: 344-7$.

7 Anderson SD, Fitch K, Perry CP, et al. Responses to bronchial challenge submitted for approval to use inhaled beta2 agonists prior to an event at the 2002 Winter Olympics. J Allergy Clin Immunol 2003;111:44-9.

8 Rundell KW, Anderson SD, Spiering BA, et al. Field exercise vs laboratory eucapnic voluntary hyperventilation to identify airway hyperresponsiveness in elite cold weather athletes. Chest 2004;125:909-15.

9 International Olympic Committee Medical Commission. Beta2 adrenoceptor agonists and the Olympic games in Athens. www.olympic.org (accessed January-April 2004).

10 Rundell KW, Wilber RL, Szmedra L, et al. Exercise-induced asthma screening of elite athletes: field vs laboratory exercise challenge. Med Sci Sports Exerc 2000;32:309-16.

11 Argyros GJ, Roach JM, Hurwitz KM, et al. Eucapnic voluntary hyperventilation as a bronchoprovocation technique: development of a standarized dosing schedule in asthmatics. Chest 1996;109:1520-4.

12 Anderson SD, Daviskas E. The mechanism of exercise-induced asthma is ... J Allergy Clin Immunol 2000;106:453-9.
13 Kikawa $Y$, Hosoi $S$, Inoue $Y$, et al. Exercise-induced urinary excretion of leukotriene E4 in children with atopic asthma. Pediatr Res 1991;29:455-9.

14 Reiss TF, Sorkness CA, Stricker W, et al. Effects of montelukast (MK-0476), a potent cysteinyl leukotriene receptor antagonist, on bronchodilation in asthmatic subjects treated with and without inhaled corticosteroids. Thorax 1997; 52:45-8.

15 Jones TR, Labelle $M$, Belley $M$, et al. Pharmacology of montelukast sodium (Singulair), a potent and selective leukotriene D4 receptor antagonist. Can J Physiol Pharmacol 1995;73:191-201.

16 Leff JA, Busse WW, Pearlman D, et al. Montelukast, a leukotriene-receptor antagonist, for the treatment of mild asthma and exercise-induced bronchoconstriction. N Engl J Med 1998;339:147-52.

17 Villaran C, O'Neill SJ, Helbling A, et al. Montelukast versus salmeterol in patients with asthma and exercise-induced bronchoconstriction. J Allergy Clin Immunol 1999;104:547-53.

18 Melo RE, Sole D, Naspitz CK. Exercise-induced bronchoconstriction in children: montelukast attenuates the immediate-phase and late-phase responses. J Allergy Clin Immunol 2003;111:301-7.

19 Peroni DG, Piacentini GL, Ress M, et al. Time efficacy of a single dose of montelukast on exercise-induced asthma in children. Pediatr Allergy Immunol 2002; 13:434-7.

20 Reiss TF, Hill JB, Harman E, et al. Increased unrinary excretion of LTE4 after exercise and attenuation of exercise-induced bronchoconstriction by montelukast, a cysteinyl leukotriene antagonist. Thorax 1997:52:130-5.

21 Cheng H, Leff JA, Amin R, et al. Pharmacokinetics, bioavailability, and safety of montelukast sodium (MK-0476) in healthy males and females. Pharm Res 1996;13:445-8.

22 Crapo RO, Casaburi R, Coates AL, et al. Guidelines for methacholine and exercise challenge testing - 1999. Am J Respir Crit Care Med 2000; 161:309-29.

23 Sterk PJ, Fabbri LM, Quanjer PH, et al. Airway responsiveness: standardized challenge testing with pharmacological, physical and sensitizing stimuli in adults. Eur Respir J 1993:6:53-83.

24 Folgering $\mathrm{H}$, Palange $\mathrm{P}$, Anderson $\mathrm{S}$. Clinical exercise testing with reference to lung diseases: indications and protocols. Eur Respir Mon 1997;6:51-71.

25 Hurwitz KM, Argyros GJ, Roach JM, et al. Interpretation of eucapnic voluntary hyperventilation in the diagnosis of asthma. Chest 1995; 108:1240-5.

26 Helenius IJ, Tikkanen $\mathrm{HO}$, Haahtela T. Occurrence of exercise induced bronchospasm in elite runners: dependence on atopy and exposure to cold air and pollen. Br J Sports Med 1998;32:125-9.

27 Beck KC, Offord KP, Scanlon PD. Bronchoconstriction occurring during exercise in asthmatic subjects. Am J Respir Crit Care Med 1994;149:352-7.

28 Sue-Chu M. Sandsund M, Holand B, et al. Montelukast does not affect exercise performance at subfreezing temperature in highly trained non-asthmatic endurance athletes. Int J Sports Med 2000;21:424-8.

29 Drazen JM. Leukotrienes as mediators of airway obstruction. Am J Respir Crit Care Med 1998;158:S193-200.

30 Manning PJ, Watson RM, Margolskee DJ, et al. Inhibition of exercise-induced bronchoconstriction by MK-571, a potent leukotriene D4-receptor antagonist. N Engl J Med 1990;323:1736-9.

31 Finnerty JP, Wood-Baker R, Thomson $\mathrm{H}$, et al. Role of leukotrienes in exerciseinduced asthma. Inhibitory effect of $\mathrm{ICl} 204219$, a potent leukotriene D4 receptor antagonist. Am Rev Respir Dis 1992;145:746-9.

32 Israel E, Dermarkarian R, Rosenberg $M$, et al. The effects of a 5 -lipoxygenase inhibitor on asthma induced by cold, dry air. N Engl J Med 1990;323:1740-4

33 Dahlen SE, Dahlen B, Eliasson E, et al. Inhibition of allergic bronchoconstriction in asthmatics by the leukotriene-antagonist ICl-204,219. Adv Prostaglandin Thromboxane Leukot Res 1991;21A:461-4

34 Szczeklik A, Stevenson DD. Aspirin-induced asthma: advances in pathogenesis, diagnosis, and management. J Allergy Clin Immuno 2003;111:913-21; quiz 922. 